\title{
The waste energy recovery, an energy-efficient solution for the industrial sector
}

\author{
Adriana Tokar ${ }^{1, *}$, Dan Negoiţescu ${ }^{2 *}$, Marius Adam ${ }^{1 *}$, Dănuţ Tokar $^{1 *}$, Arina Negoiţescu $^{3 *}$ \\ ${ }^{1}$ Faculty of Civil Engineering, Traian Lalescu Street, No. 2, 300223 Timișoara, Romania \\ ${ }^{2}$ Faculty of Electronics and Telecommunications Engineering, Vasile Parvan Street, No. 2, 300223 Timișoara, Romania \\ ${ }^{3}$ Faculty of Mechanical Engineering, Mihai Viteazu Street, No. 1, 300222 Timișoara, Romania
}

\begin{abstract}
One of the world's topical issues is the necessity of energy consumption reduction in order to conserve less and less natural resources and protect the environment. The article deals with the need to develop the waste energy recovery solutions that reduce energy consumption among the industrial consumers. In order to identify the sources with recoverable potential and establish energy recovery solutions, thermography of the hot air and hot gas exhaust circuits from industrial technological facilities were performed, followed by monitoring the operation parameters and measuring the energy consumption. The energy consumption reduction is analyzed by comparative interpretations of the hourly consumption, before and after applying the optimal recovery solution. The analysis of the results revealed that the waste energy recovery during the technological facilities operation has, besides the economic benefit, also other positive energetic effects, technical and not at least ecological ones.
\end{abstract}

\section{Introduction}

Considering the increasing global energy consumption and the fact that conventional energy sources are not inexhaustible, global policies and strategies have imposed and continue to impose more severe limits on the primary and final energy consumption.

From the EU's point of view, the Commission is monitoring progresses towards achieving national energy efficiency targets and implementation of the EU directives by 2020 . As a result of the assessments done by EU on the member states regarding the trends which must be reached in the industrial field until 2020, in Romania during 2005-2015 the primary and final energy consumption decreased faster than the imposed required rate. Romania has made progress in achieving energy savings and the energy intensity has been halved [1].

One of the recommendations proposed by the Romanian energy policy makers is to identify measures to increase energy efficiency among large industrial consumers. In this respect, the energy auditing of energy-saving installations and equipment establishes the economic feasibility of these measures [2].

The energy consumption limitation also contributes to greenhouse gas emissions (GHG) reduction and implicitly the global warming effect limitation [3].

In order to reduce the fuel consumption and pollutant emissions in the industrial sector, a solution is the recovery systems used to recover the waste energy from technological processes. Part of the energy generated by industrial equipment and processes is wasted and is transferred to the environment by conduction, convection and radiation [4]. In most technological processes, the most significant sources of waste heat are combustion gases and hot air exhausted through ventilation systems. For this purpose, the article presents the results of the experimental research conducted in order to identify the potentially recoverable sources to an industrial consumer. Following the analysis, the possible solutions for the waste energy recovery have been established [5-9]. The results of the comparative analysis were the basis of the optimal solution implementation, which ultimately contributed to the quantitative assessment of the total energy consumption reduction [10-12].

\section{Presentation of technological endowments}

Experimental research was carried out to an economic agent endowed with dyeing/drying booths (DDBs) which consume natural gas and electricity during its operation. The DDBs installed electrical power values are of $5.5 \mathrm{~kW}$ and $13.5 \mathrm{~kW}$ and the thermal ones of (246-315) kW [8]. The fan provides inlet air flows of $8400 \mathrm{~m}^{3} / \mathrm{h}$ and $1680 \mathrm{~m}^{3} / \mathrm{h}$ and exhausted ones of $8400 \mathrm{~m}^{3} / \mathrm{h}$ and $13440 \mathrm{~m}^{3} / \mathrm{h}$. The DDB burners gas flows (G20 natural gas) are of $26.74 \mathrm{Nm}^{3} / \mathrm{h}$ and $34.24 \mathrm{Nm}^{3} / \mathrm{h}$ [8].

The DDB operates at adjustable and thermostatic temperatures according to the technological process carried out inside it (dyeing or drying).

The technological processes development at the analyzed economic agent, for dyeing and drying the metal products and fiberglass reinforced resins, have a negative impact on the environment both from the thermal point of view -

\footnotetext{
* Corresponding author: adriana.tokar@upt.ro
} 
the heat exhausted with the foul air and hot gases - and chemical point of view - concentration of pollutant gases exhausted into the atmosphere.

Although the agent has taken measures to improve the dyeing / drying process and production systematization which have led to lower energy consumption and pollutant emissions, it has nevertheless been identified as necessary to reduce energy consumption by recovering the waste energy [8].

Because the economic agent is an important energy consumer (200MWh/year), we have implemented heat recovery solutions and conversion of waste energy through the exhaust systems in order to reduce the energy consumption and pollutant emissions [11]. The research aimed to highlight the economic sustainability by recovering the waste energy resulted from the production activities.

\section{Objectives and stages of the research}

The waste heat is recorded mostly in the industrial sector. Due to the need to reduce energy costs and to minimize the impact associated with waste products, the most economic agents pay attention to the recovery and reuse of visible waste products (metal, paper, polyethylene, etc.), but most of the time the waste energy recovery (residual heat, kinetic and potential energy of technological fluids) is neglected.

For this reason, it is necessary to develop a regulatory framework to provide the industry with a methodology for assessing the production activities and their related facilities that produce waste heat, simultaneously with compatibility analysis of facilities which contain equipment for the waste energy recovery. It is also necessary for the productive sector to receive technical support in order to assess and highlight the economic benefits.

The economic opportunity to recover the waste energy from the industrial activities is demonstrated by the research carried out to the analyzed economic agent.

\subsection{The research flow}

Identifying and assessing the opportunities for recovering the waste energy to the DDB of the economic agent required a complex approach, especially regarding the optimal solution selection which has to ensure the greatest benefits both from the point of view of energy consumption reduction through the waste energy recovery, and of the return on investment one.

The assessment framework was conducted in five distinct phases, which are summarized in Figure 1.

For the assessment to be as relevant as possible, the research was conducted over a 2-year period (October 2016- October 2018), during which all five phases were reviewed and analyzed.

In this respect, the behavior of the industrial technological equipment (ITE), such as DDB and installed equipment was studied both in the cold season and the warm one.
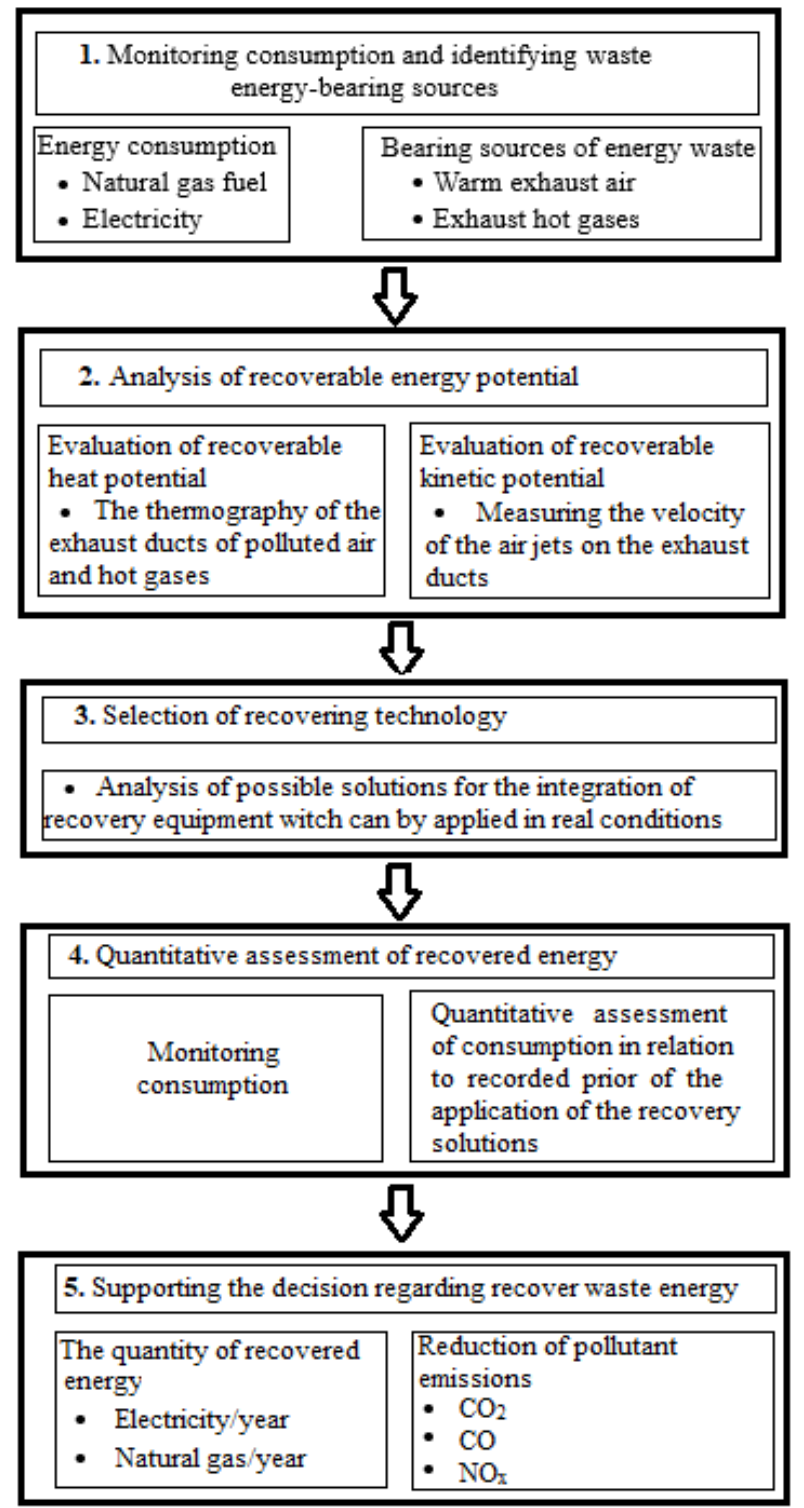

Fig. 1. Framework for energy recovery assessment

Starting from the monitoring of energy consumption and the identification of the sources of energy waste at the analyzed ITD, possible recovery solutions were established. The comparative assessments led to the establishment of an optimal solution that can be implemented to the economic agent without significant modification of the analyzed technological installations.

\subsection{The equipment used}

In order to monitor the input/output parameters of the analyzed DDB, measuring and control devices (AMC) have been installed.

For the energy consumption quantitative assessment, electricity meters were installed inside the air transformer switch board (CST0410E type meter) and the control panels of the analyzed DDBs (T2-CA43 type meter). For monitoring the natural gas fuels consumption G10 type meters were installed.

The recording of the DDB operating hours was carried out by installing electromechanical hour meters - Revalco, 
Hour Meter and AEG UWZ 48 - on their control panels. The DDB indoor / outdoor temperatures and foul air temperature monitoring was performed by installing temperature recorders - YCT R1-6111Temperature + RTD Temperature Data Logger - to which PT 100 temperature probes were connected. Data collection and storage was performed by using a 5690-2M data acquisition system.

For obtaining thermal images in order to identify the sources with recoverable heat potential was achieved by using the FLIR thermal imaging camera.

The determination of the exhausted air jets kinetic potential implied the measurement of the air velocity with portable anemometers placed on a graduated ruler device. Measurements of pollutant emissions exhausted into the atmosphere by the DDB burners was performed with a Testo $350 \mathrm{~S}$ gas analyzer [10 and 12].

The collected data was the basis of drawing up the consumption graphs and plotting the variations of the monitored operating parameters required for establishing the recuperative solutions and for the quantitative assessment of the recovery rate [7 and 12].

The input data monitoring was done by reading energy meters and hourly meters during the productive cycle over a certain time frame so as to be able to determine an average energy consumption for a given type of activity.

\subsection{The identification of sources with recoverable energy potential}

Before defining a framework for identifying the recoverable energy potential and assessing the opportunities for the waste energy recovery / reuse, an analysis of energy consumption categories and waste management methods resulting from the technological process was carried out. The identification of sources with recoverable potential was made in two directions, namely: recoverable heat potential and recoverable kinetic one $[6$, $11]$.

The assessment of the recoverable heat potential was carried out by analyzing the thermal images of the foul hot air exhaust ducts inside the DDB and of those of flue gases - between the hot air generator and the chimney - pictures obtained by infrared thermography. The thermal images obtained for the analyzed exhaust ducts are shown in Figure 2 (foul hot air - Figure 2.a and flue gases - Figure 2.b [11]).

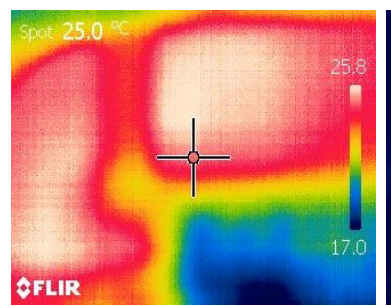

a)

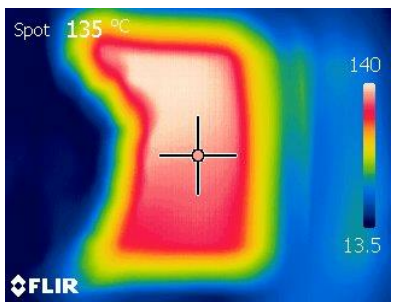

b)
Fig. 2. Thermal graphics of the circuits

The assessment of the foul air jet kinetic potential exhausted into the atmosphere by the fan of the DDB exhaust system was done by measuring the air jet velocity at various distances away from the exhaust grid. The recorders highlighted air jet velocities variations at the output of the exhaust ducts between $15 \mathrm{~m} / \mathrm{s}$ and $8 \mathrm{~m} / \mathrm{s}$ for distances between $20 \mathrm{~cm}$ and $200 \mathrm{~cm}$ from the exhaust grid [6].

Following the assessments regarding the recoverable thermal and kinetic potential, there was noted that the analyzed technological processes take place at high temperatures and therefore these sources are important sources of waste heat. On the other hand, by ensuring the climatic parameters inside the DDB involves the conveying of an air constant flow with kinetic potential that can be convert into power electrical.

\section{Waste energy survey}

Based on the consumptions in the initial operational state monitoring and the identification of sources with recoverable energy potential, by passing through the phases presented in Figure 1, various solutions for energy recovery were established, monitoring and evaluated. The optimal solution of waste energy recovery, applicable without major changes, is the installing of an economizer on the combustion gases exhaust system and the using of the recovered thermal energy for preheating the fresh air introduced into the DDB, together with the installing of a wind facility on the foul air exhaust duct in order to convert the kinetic potential into power electrical [7]. The waste energy recovery rate was assessed by comparing the electrical power and combustible natural gases hourly consumptions before the optimal system implementation (year 2017) and after (year 2018) (Figure 3) [12].

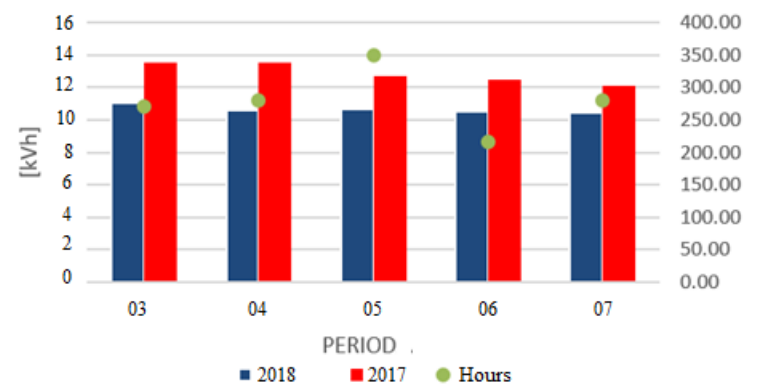

a)

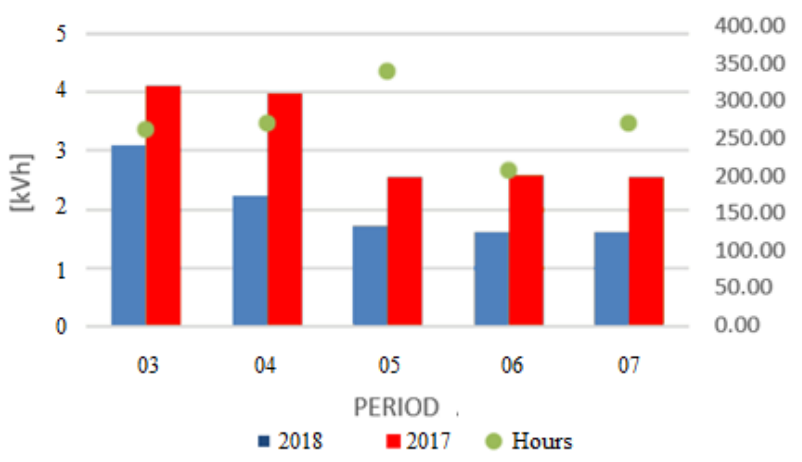

b)

Fig. 3. Hourly energy consumption a) Electrical Power, b) Natural gas 
The comparative analysis of the results obtained before and after the implementation of the recuperative system at the analyzed DDB shows a reduction in the combustible natural gas consumption of $12966.99 \mathrm{kWh}$ and a reduction in the electrical power one of $2279.81 \mathrm{kWh}$, thus achieving a total saving of 800 Euro [7].

On the other hand, the wind micro-power plant, which operated for $1039 \mathrm{~h}$ at a power of $250 \mathrm{Wh}$, achieved a saving of 61 Euro [7].

Considering that the analyzed economic agent has five DDBs, it can be estimated a total saving of approximately 4300Euro over the monitored 6 months, which would represent an annual saving of approximately 8600 Euro [7]. In addition to economic issues, the recovery of waste energy resulted during the operation of the analyzed ITD also generates technical, energetic and, last but not least, environmental effects. By cooling the combustion gases by intercalating the recuperative equipment on the exhaust gas circuit has led to the reduction in the pollutant emissions concentration of $\left(\mathrm{CO}_{2}, \mathrm{CO}\right.$ and NOx $)$ [7, 10 and 12]. From an energetic point of view, the main indicator on the basis of which the efficiency of the waste energy recovery solution was assessed is the equivalent in fuel of the energy saved (quantity of natural gas and electricity), determined as the difference between the fuel consumption before and after the recovery process.

\section{Conclusions}

The economizer insertion within the DDB installation for air heating / preheating mainly represents for the economic agent a reduction in fuel consumption and costs, as well as an upgrade to a new technology that contributes to an increase in recovery rate. On the other hand, the integration of the wind power plant leads to the conversion of exhaust air jets kinetic energy into electrical power, providing a fraction of the consumption required to supply the DDB lighting system. In conclusion, the reduction of fuel consumption and the economic agent's awareness of the need to recover the waste energy and to reduce pollution are the main objective of this analysis.

\section{Aknoledgement}

This work was supported by a grant of the Romanian National Authority for Scientific Research and Innovation, CNCS/CCCDI - UEFISCDI, project number PNIII-P2-2.1-BG2016-0254, No. 74BG / 2016, within PNCDI III.

\section{References}

1. $* * *$, European Commission, Directive in accordance with Article 24 (3) of the Energy Efficiency Directive 2012/27 / EU, Brussels, 23.11 2017 COM (2017) 687 final, http://ec.europa.eu, accessed in 30.10.2018.
2. ***, Energy Strategy of Romania 2016-2030, with the perspective of 2050, http://media.hotnews.ro, accessed in 30.10.2018.

3. ***, Elements of Energy Strategy for 2011-2035 Strategic directions and objectives in the electricity sector, www.minind.ro/dezbateri_publice, accessed 15.10.2018.

4. ***, Waste Heat Recovery: Technology and Opportunities in US Industry, US Department of Energy, Industrial Technologies Program Prepared by BCS, Incorporated March 2008, https://www.eere.energy.gov, accessed in 30.10.2018, (2008).

5. A. Negoițescu, A. Tokar, D. Negoițescu, C. Hamat, Energy Efficiency of Technological Equipment at the Economic Agent by Identifying the Points with Recoverable Heat Potential, Analele Universităţii "Eftimie Murgu" Reşiţa, Anul XXIV, Nr. 1, ISSN 1453 - 7397, pp. 257-266, (2017).

6. D. Negoițescu, D. Tokar, A. Tokar, A. Negoițescu, Aspects regarding the Valorization of the Air Jets Energy Potential from Industrial Technological Equipment, Analele Universităţii "Eftimie Murgu" Reşiţa, Anul XXIV, Nr. 1, ISSN 1453 - 7397, pp. 267-277, (2017).

7. A. Tokar, Scientific and Technical Report on project implementation No. 74BG / 2016, cod: PN-III-P22.1-BG-2016-0254, in Stage I, (2016), in Stage II, (2017), in Stage III, (2018).

8. A. Tokar, A. Negoițescu, D. Negoițescu, M. Adam, An Approach Regarding the Application of Energy Efficiency Measures to Industrial Consumers, Conferinţa "Instalaţii pentru Construcţii şi Confortul Ambiental”, Ediţia a 26-a, Timişoara, România, pp. 223-230, (2017).

9. A. Tokar, A. Negoițescu, A. Retezan, S. Doboși, Concept of saving natural gas consumption in painting/drying cabins, International Conference "Modern Science and Energy" SME 2017, Energy Production, Transport and Use, 36th Edition, pp. 217224, Publishing House Risoprint, ISSN 2066-4125, Cluj-Napoca, Mai, (2017).

10. A. Tokar, A. Negoițescu, D. Negoițescu, M. Adam, A Solution to Reduce Pollutant Emissions by Recovering the Flue Gases Waste Heat, Analele Universităţii "Eftimie Murgu" Reşiţa, Anul XXV, Nr. 1, ISSN 1453 - 7397, pp. 126-131, (2018).

11. A. Tokar, A. Negoițescu, A. Rusen, Solutions to Recover the Energy Lost to an Industrial Consumer, IOP Conf. Ser.: Mater. Sci. Eng. 393012078 (2018).

12. A. Tokar, Final Report on project implementation No. 74BG / 2016, cod: PN-III-P2-2.1-BG-20160254, in Stage III, (2018). 